\title{
Uncertainty of the Offshore Wind Energy Resource Assessment due to Long-term Variability
}

\author{
Bo JIANG* \\ National Ocean Technology Center \\ Tianjin, China \\ E-mail:qdjiangbo@163.com
}

\author{
Song ZHANG, He WU and Jie Ding \\ National Ocean Technology Center \\ Tianjin, China
}

\author{
Ping-ping HOU \\ The Institute of Seawater Desalination and Multipurpose \\ Utilization, SOA \\ Tianjin, China \\ E-mail:64990953@qq.com
}

\begin{abstract}
The long-term uncertainty of offshore wind energy resource in Sansha sea area was studied using the 24-year (January $1^{\text {st }}, 1988$-December $\left.31^{\text {st }}, 2011\right)$ CCMP (crosscalibrated, multi-platform) wind field data with spatial and temporal resolutions of $0.25^{\circ} \times 0.25^{\circ}$ and $6 \mathrm{~h}$, respectively. In this paper, three kinds of numerical approaches used for quantify the uncertainty of the offshore wind energy resource that were produced, i.e. statistic analysis, Weibull distribution function and representative year. Their performance was compared through the average of the whole dataset according to the criterions such as relative errors $(R E)$ and correlation coefficient $(R)$. The results show that, 1$)$ Weibull annual wind speed and energy density during the 24-year in Sansha sea area are found to be less than $0.05 / 0.1 \%$ mean $R E$ and $1.5 / 4.5 \%$ maximum $R E$ with nearly 1.0 correlation coefficient, respectively, in comparison with statistic analysis. 2) For the past 24-year, the wind speed and wind energy density have followed a significant increasing trend in Xisha and Zhongsha (at the $90 \%$ confidence level), and has weak positive trend in Nansha. 3) Representative year approach can accurate assess the 24-year wind energy resource in Sansha according to less than or equal to $0.8 \% R E$ of mean wind speed and $4.2 \% R E$ of energy density,respectively. 4)The uncertainty is related to the long-term variability of the wind climate, even if a 15-year average, the maximum $R E$ of wind energy density can exceed $6.0 \%$ in Nansha.
\end{abstract}

Keywords-Offshore wind energy; Resource assessment; CCMP wind field data; Uncertainty analysis

\section{INTRODUCTION}

Offshore wind energy resource assessment is an important first step before selecting a site to build offshore wind farm. The evaluation results is directly related to the investment and economic benefit after the wind farm was put into operation. Uncertainties exist due to long-term variability in addition to the inherent uncertainties in the measurement of wind speed, the air density, simplistic wind shear extrapolation, wind modeling and the wind speed density function[1-3].
The purpose of the uncertainty analysis is to quantify the uncertainty of the offshore wind energy resource estimates that are produced. The offshore wind energy resource is defined by a multitude of parameters, for each of which an uncertainty can be calculated. The choice of parameters for which the uncertainty should be calculated depends on the purpose of the offshore wind energy resource assessment. However, as a minimum, the uncertainty of the mean wind speed and mean wind energy density shall be calculated.

In this paper, the long-term uncertainty of offshore wind energy resource in Sansha sea area is studied using the 24year $\left(\right.$ January $1^{\text {st }}, 1988$-December $\left.31^{\text {st }}, 2011\right)$ CCMP (crosscalibrated, multi-platform) wind field data with spatial and temporal resolutions of $0.25^{\circ} \times 0.25^{\circ}$ and $6 \mathrm{~h}$, respectively.

\section{WIND FIELD DATA}

The CCMP ocean surface wind velocity data set was a result of an investigation funded by NASA's (National Aeronautics and Space Administration) Making Earth Science data records for Use in Research Environments (MEaSUREs) Program[4]. The data set has been evaluated and utilized extensively in meteorology and oceanography[59]. It combines data derived from SSM/I (Special Sensor Microwave Imager), AMSRE (Advanced Microwave Scanning Radiometer Earth observing system), TRMM TMI (Tropical Rainfall Measuring Mission Microwave Imager), Quikscat and other missions using a VAM (variational analysis method) to produce a consistent climatological record of ocean surface vector winds. All observations are referenced to a height of 10 meters. For CCMP, multiinstrument ocean surface wind velocity data set, with spatial and temporal resolutions of $0.25^{\circ} \times 0.25^{\circ}$ and $6 \mathrm{~h}$, respectively, the period extending from July 2, 1987 through December 31,2011 , and the area covering $78.5^{\circ} \mathrm{S}-78.5^{\circ} \mathrm{N}$, $180^{\circ} \mathrm{W}-180^{\circ} \mathrm{E}$ 


\section{METHODS}

\section{A. Area of Interest}

The South China Sea was chosen for this study and the area of interest is Sansha sea area which is located in the western, middle and southern part of it. South China Sea with a surface area of $3,500,000 \mathrm{~km}^{2}$ is the Chinese largest sea. It is bordered to the north by Asian continent, to the west by Indochina Peninsula, to the south by Kaliman Island, to the southeast by Palawan, to the east by Luzon Island. This area is rich in energy wealth as well as fishery resources, navigation and military affairs. Hence, it is considered as an area where the investigation of providing offshore wind energy is very important.

Sansha sea area is composed of three parts, Xisha (the area covering $\left.111^{\circ} \mathrm{E}-113^{\circ} \mathrm{E}, \quad 15.5 \mathrm{~N}-17^{\circ} \mathrm{N}\right)$, ZHongsha $\left(113.5^{\circ} \mathrm{E}-115^{\circ} \mathrm{E}, 15.5^{\circ} \mathrm{N}-16.5^{\circ} \mathrm{N}\right)$ and Nansha $\left(109.5^{\circ} \mathrm{E}-\right.$ $118^{\circ} \mathrm{E}, 3.5^{\circ} \mathrm{N}-12^{\circ} \mathrm{N}$ ) sea area, respectively. This research used CCMP ocean surface wind field data set between $1 / 1 / 1988$ and $12 / 31 / 2011$.

\section{B. Deterministic Approach without Considering the Uncertainties}

In order to compare the performance, we will consider statistic analysis, two-parameter Weibull distribution function and representative year approach to calculate the mean wind speed and energy density without accounting for uncertainties.

1) Statistic analysis approach

The statistic approach to calculate the mean wind speed is expressed as:

$$
\bar{v}=\frac{1}{n} \sum_{i=1}^{n} v_{i}
$$

Where $\bar{v}$ is the mean wind speed $(\mathrm{m} / \mathrm{s}), n$ is the number of data points(dimensionless), and $v_{i}$ is the wind speed at the $i^{\text {th }} \operatorname{record}(\mathrm{m} / \mathrm{s})$.

Mean wind energy density is calculated as follows:

$$
P=\frac{1}{2 n} \sum_{i=1}^{n}\left(\rho \cdot v_{i}^{3}\right)
$$

Where $P$ is the wind energy $\operatorname{density}\left(\mathrm{W} / \mathrm{m}^{2}\right)$, and $\rho$ is the standard sea-level air density $\left(1.225 \mathrm{~kg} / \mathrm{m}^{3}\right)[6][10]$.

2) Weibull distribution function approach

Two-parameter Weibull distribution can be described by its probability density function as follows:

$$
f(v)=\frac{k}{c}\left(\frac{v}{c}\right)^{k-1} \exp \left[-\left(\frac{v}{c}\right)^{k}\right]
$$

Where $v$ is the wind $\operatorname{speed}(\mathrm{m} / \mathrm{s}), k$ is the shape parameter (dimensionless), and $C$ is the scale parameter $(\mathrm{m} / \mathrm{s})$.

Weibull parameter of empirical method is estimated by[11-13]:

$$
\begin{aligned}
& k=\left(\frac{\sigma}{v}\right)^{-1.086} \\
& C=\frac{\bar{v}}{\Gamma(1+1 / k)}
\end{aligned}
$$

Where $\sigma$ is the standard deviation of wind $\operatorname{speed}(\mathrm{m} / \mathrm{s})$, and $\Gamma()$ is the Gamma function.

The Weibull mean wind speed and energy density are defined in Eq. (6) and Eq. (7), respectively.

$$
\begin{gathered}
v_{W}=c \Gamma(1+1 / k) \\
P_{W}=\frac{1}{2} \rho c^{3} \Gamma\left(1+\frac{3}{k}\right)
\end{gathered}
$$

Where $v_{W}$ is the Weibull mean wind $\operatorname{speed}(\mathrm{m} / \mathrm{s})$, and $P_{W}$ is the Weibull mean wind energy density. For detailed studies on estimating Weibull parameters or using other models, refer to[11].

3) Representative year approach

The year of annual wind speed nearest to the 24-year average is defined as the mean wind speed year[14-16]. The year of the maximum/minimum annual wind speed of the 24 year is defined as the maximum/minimum wind speed year[14-16]. The mean, maximum and minimum wind speed year are collectively called the "representative year". The three years are fairly representative of the whole period.

\section{RESULTS AND DISCUSSIONS}

\section{A. Interannual Variability of Wind Speed and Energy Density}

Comparison of the 24-year series of the statistic and Weibull wind speed and energy density are illustrated in Fig. 1 and 2, respectively. As seen, there is a good agreement between the statistic and Weibull wind parameters in the 24 year. In addition, some error metrics for quantitative evaluation of the Weibull performance were used. These include correlation coefficient $(R)$ and relative errors $(R E)$ given as: 


$$
\begin{gathered}
R=\frac{\sum_{i=1}^{24}\left(x_{i}-\bar{x}\right)\left(y_{i}-\bar{y}\right)}{\sqrt{\sum_{i=1}^{24}\left(x_{i}-\bar{x}\right)^{2} \sum_{i=1}^{24}\left(y_{i}-\bar{y}\right)^{2}}} \\
R E=\frac{\left|x_{i}-y_{i}\right|}{x_{i}} \times 100 \%
\end{gathered}
$$

Where $x_{i}$ is the statistic annual value at $i$ year, $y_{i}$ is the Weibull annual value at $i$ year, $\bar{x}$ and $\bar{y}$ are the mean value of statistic and Weibull of the 24 years, respectively.

The errors are list in Table I. According to the errors, the wind speed and energy density calculated using statistic and Weibull are nearly similar. The high values of $R$ for wind parameters, which are in close proximity to 1.0 , imply that the Weibull approach performs well in assessment of wind energy resource. In addition, considering the mean and maximum $R E$ values, which are less than $0.05 / 0.1 \%$ for wind speed and $1.5 / 4.5 \%$ for energy density, respectively, so the Weibull approach has the ability of wind energy assessment in the study area.

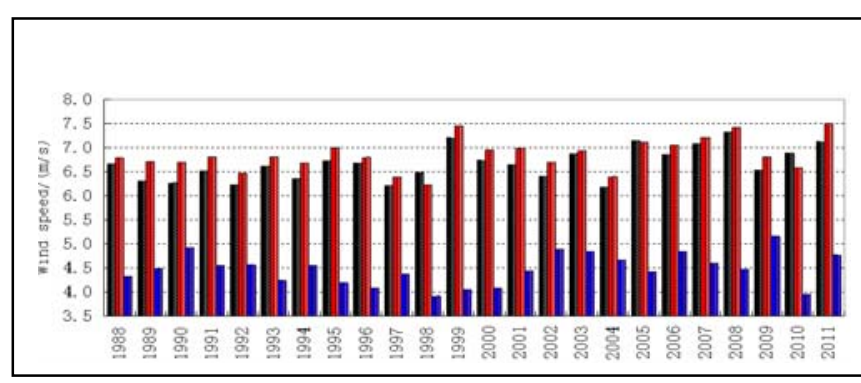

Figure 1. Comparison of the statistic and Weibull energy density:black is Xisha, red is Zhongsha, and blue is Nansha; is statistic and is Weibull

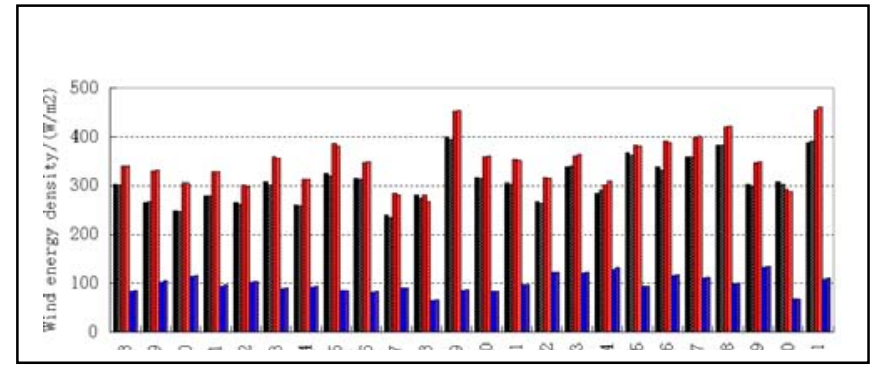

Figure 2. Comparison of the statistic and Weibull wind speed:black is Xisha, red is Zhongsha, and blue is Nansha; is statistic and is Weibull

TABLE I. COMPARISON OF THE WIND PARAMETERS ERRORS BETWEEN STATISTIC AND WEIBULL IN SANSHA(1988-2011)

\begin{tabular}{|c|c|c|c|c|c|c|}
\hline \multirow{2}{*}{ Sea area } & \multicolumn{3}{|c|}{ Wind speed } & \multicolumn{3}{c|}{ Wind energy density } \\
\cline { 2 - 4 } & \multirow{2}{*}{$\boldsymbol{R}$} & \multicolumn{2}{|c|}{$\boldsymbol{R E} / \mathbf{\%}$} & \multirow{2}{*}{$\boldsymbol{M}$} & \multicolumn{2}{|c|}{$\boldsymbol{R E} / \%$} \\
\cline { 3 - 4 } \cline { 6 - 7 } & & mean & Max & & mean & Max \\
\hline Xisha & 1.000 & 0.03 & 0.06 & 0.997 & 1.1 & 2.5 \\
\hline Zhongsha & 1.000 & 0.04 & 0.06 & 0.997 & 0.9 & 4.0 \\
\hline Nansha & 1.000 & 0.04 & 0.09 & 0.998 & 1.5 & 4.5 \\
\hline
\end{tabular}

Inter-annual variability of wind speed and wind energy density in Sansha sea area are shown in Fig. 3 and 4. These displays the annual wind speed and energy density level expressed as a percentage of the 24-year average, respectively. It can be seen that the annual wind speed and energy density varied by as much as $15 / 36 \%$ from the average, respectively. For the past 24-year, the wind speed and energy density have followed a significant increasing trend in Xisha and Zhongsha sea area (at the $90 \%$ confidence level), and has weak positive trend in Nansha sea area. The maximum magnitude of the increase locates in Xisha sea area, with the wind speed and energy density having increased trends of approximately $0.41 / 1.20 \%$ per year, respectively, and $R$ is $0.57 / 0.58$. Median is Zhongsha sea area, with the wind speed and energy density increase reaching $0.28 / 0.81 \%$ per year and $R$ being $0.41 / 0.40$, respectively. Minimum is Nanshan sea area, with the weak positive increase $(0.22 / 0.74 \%$ per year).

If three offshore wind farms were built in Xisha, Zhongsha and Nansha sea area in 2000 with a 12 year lifespan, respectively, with a yield estimation based on the preceding 12 years, the power while the farm operated would be $13 / 9 / 18 \%$ higher than anticipated.

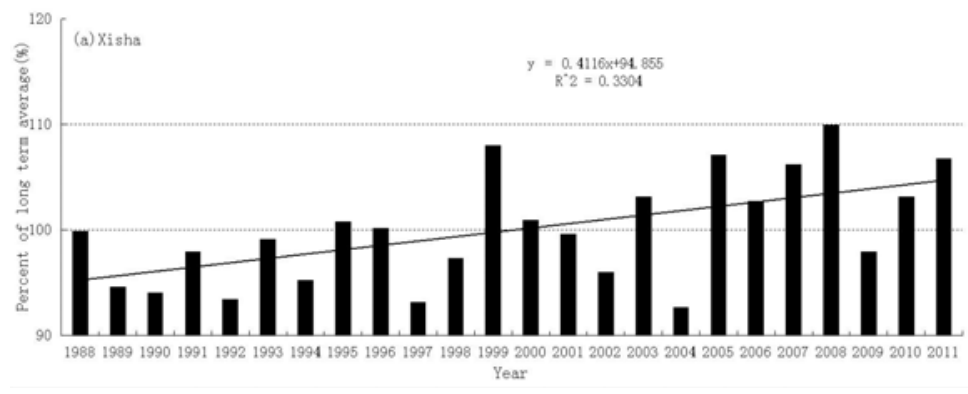




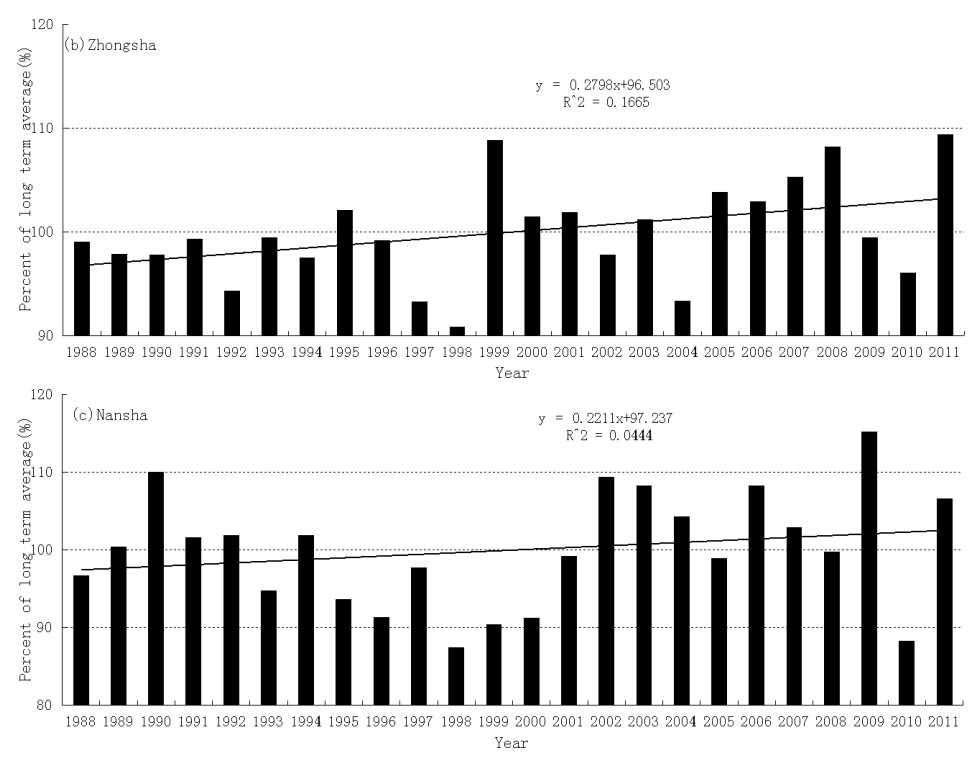

Figure 3. Inter-annual variability of wind speed in Sansha
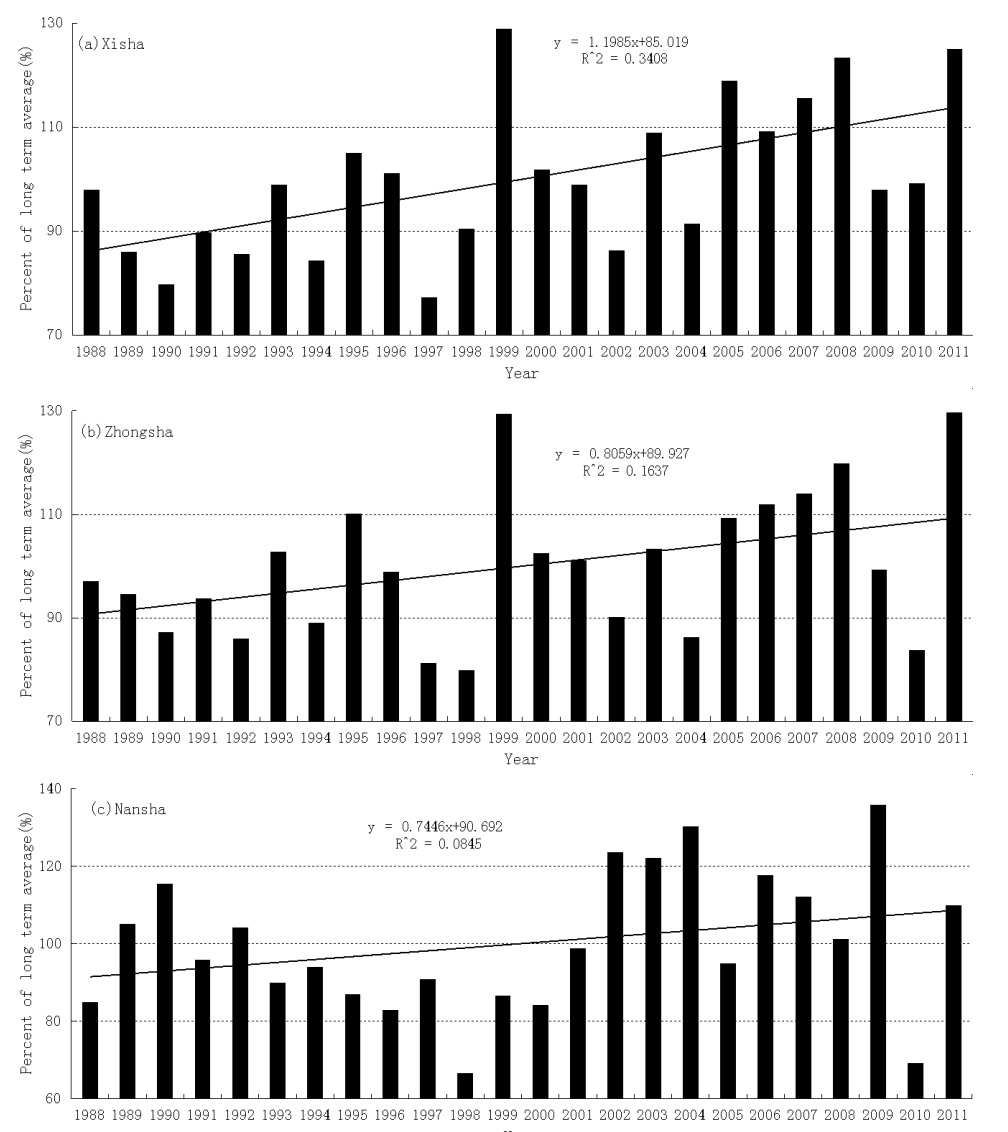

Figure 4. Inter-annual variability of wind energy density in Sansha 


\section{B. Long-term Offshore Wind Resource Uncertainty}

The representative year in Sansha sea area during the past 24-year are listed in Table II and the $R E$ of wind parameters between the statistic and representative year are listed in Table III. It is seen that the $R E$ of mean wind speed and energy density is less than or equal to $0.8 / 4.2 \%$, respectively, implying that representative year approach can accurate assess the long term wind energy.

TABLE II. THE REPRESENTATIVE YEAR IN SANSHA(1988-2011)

\begin{tabular}{|c|c|c|c|}
\hline Sea area & $\begin{array}{c}\text { Minimum wind } \\
\text { speed year }\end{array}$ & $\begin{array}{c}\text { Mean wind } \\
\text { speed year }\end{array}$ & $\begin{array}{c}\text { Maximum wind } \\
\text { speed year }\end{array}$ \\
\hline Xisha & 2004 & 1988 & 2008 \\
\hline Zhongsha & 1998 & 1993 & 2011 \\
\hline Nansha & 1998 & 2008 & 2009 \\
\hline
\end{tabular}

TABLE III. COMPARISON OF THE WIND RELATIVE ERRORS $(R E)$ BETWEEN STATISTIC AND REPRESENTATIVE YEAR IN SANSHA(1988-2011)

\begin{tabular}{|c|c|c|}
\hline Sea area & $\boldsymbol{R E}$ of Wind speed/\% & $\boldsymbol{R E}$ of Energy density/\% \\
\hline Xisha & 0.8 & 4.2 \\
\hline Zhongsha & 0.03 & 4.1 \\
\hline Nansha & 0.8 & 1.1 \\
\hline
\end{tabular}

In order to highlight the improvement that a 15 -year offshore wind energy resource assessment gives over a 5 or 10 year resource assessment, rolling averages were taken over 5, 10 and 15 years from the 24-year of CCMP field data in Fig. 1 and 2. A comparison of the mean and maximum $R E$ for the 5, 10 and 15 year averages, when compared to the average of 24 years, are listed in Table IV to VI. The results show that, 1) the $R E$ of wind energy density is larger than wind speed, as much as three times, and 2) the uncertainty is related to the long-term variability of the wind climate in Sansha sea area, even if a 15-year average, the maximum $R E$ of wind energy density can exceed $6.0 \%$.

TABLE IV. COMPARISON OF RE OF WIND PARAMETERS BETWEEN THE 5, 10 AND 15 YEAR AVERAGES IN XISHA(1988-2011)

\begin{tabular}{|c|c|c|c|c|}
\hline & \multicolumn{2}{|c|}{$\boldsymbol{R E}$ of Wind speed/\% } & \multicolumn{2}{c|}{$\boldsymbol{R E}$ of Energy density/\% } \\
\hline & Mean & Max & Mean & Max \\
\hline $\begin{array}{c}\text { 5 year } \\
\text { average }\end{array}$ & 2.3 & 4.8 & 6.6 & 13.0 \\
\hline $\begin{array}{c}\text { 10 year } \\
\text { average }\end{array}$ & 1.6 & 3.4 & 4.7 & 10.2 \\
\hline $\begin{array}{c}\text { 15 year } \\
\text { average }\end{array}$ & 1.2 & 2.0 & 3.5 & 6.0 \\
\hline
\end{tabular}

TABLE V. COMPARISON OF RE OF WIND PARAMETERS BETWEEN THE 5, 10 AND 15 YEAR AVERAGES IN ZHONGSHA(1988-2011)

\begin{tabular}{|c|c|c|c|c|}
\hline & \multicolumn{2}{|c|}{$\boldsymbol{R E}$ of Wind speed/\% } & \multicolumn{2}{c|}{$\boldsymbol{R E}$ of Energy density/\% } \\
\hline & Mean & Max & Mean & Max \\
\hline $\begin{array}{c}5 \text { year } \\
\text { average }\end{array}$ & 1.8 & 3.9 & 4.8 & 10.8 \\
\hline $\begin{array}{c}\text { 10 year } \\
\text { average }\end{array}$ & 1.3 & 2.8 & 3.3 & 7.7 \\
\hline $\begin{array}{c}\text { 15 year } \\
\text { average }\end{array}$ & 0.8 & 1.5 & 2.3 & 3.9 \\
\hline
\end{tabular}

TABLE VI. COMPARISON OF RE OF WIND PARAMETERS BETWEEN THE 5, 10 AND 15 YEAR AVERAGES IN NANSHA(1988-2011)

\begin{tabular}{|c|c|c|c|c|}
\hline & \multicolumn{2}{|c|}{$\boldsymbol{R E}$ of Wind speed/\% } & \multicolumn{2}{c|}{$\boldsymbol{R E}$ of Energy density/\% } \\
\hline & Mean & Max & Mean & Max \\
\hline $\begin{array}{c}\text { 5 year } \\
\text { average }\end{array}$ & 3.9 & 8.4 & 10.0 & 17.9 \\
\hline $\begin{array}{c}\text { 10 year } \\
\text { average }\end{array}$ & 2.7 & 5.1 & 7.4 & 12.0 \\
\hline $\begin{array}{c}\text { 15 year } \\
\text { average }\end{array}$ & 1.2 & 2.2 & 2.5 & 6.1 \\
\hline
\end{tabular}

\section{CONCLUSIONS}

Based on the results and discussion above the conclusions are summarized as follows:

(1) Weibull annual wind speed and energy density during the period from 1988 to 2011 in Sansha sea area are found to be less than $0.05 / 0.1 \%$ mean relative errors $(R E)$ and $1.5 / 4.5 \%$ maximum $R E$ with nearly 1.0 correlation coefficient $(R)$, respectively, in comparison with statistic analysis.

(2) For the past 24-year, the wind speed and wind energy density have followed a significant increasing trend in Xisha and Zhongsha sea area (at the 90\% confidence level), and has weak positive trend in Nansha sea area.

(3) Representative year approach can accurate assess the 24-year wind energy resource in Sansha sea area according to less than or equal to $0.8 \%$ relative errors $(R E)$ of mean wind speed and $4.2 \% R E$ of energy density,respectively.

The uncertainty is related to the long-term variability of the wind climate in Sansha sea area, even if a 15-year average, the maximum relative errors $(R E)$ of wind energy density can exceed $6.0 \%$.

\section{ACKNOWLEDGMENT}

The CCMP wind field data set was provided by NASA's MEaSUREs Program. This study is supported by National Natural Science Foundation of Tianjin, China (Grant no. 16JCYBJC20600).

\section{REFERENCES}

[1] Bastide C. and Harding J. Energy yield assessment-are you doing it right? EWEC2007, vol. 44. Milan, 2007.

[2] Sungmoon Jung, O. Arda Vanli, and Soon-Duck Kwon, Wind energy potential assessment considering the uncertainties due to limited data. Applied Energy, vol. 102, pp. 1492-1503, 2013.

[3] Wolf-Gerrit Früh, Long-term wind resource and uncertainty estimation using wind records from Scotland as example, Renewable Energy, vol. 50, pp. 1014-1026, 2013.

[4] Cross-Calibrated Multi-Platform (CCMP) Ocean Surface Wind Components. http://apdrc.soest.hawaii.edu/datadoc/ccmp_6hourly.php

[5] Atlas, R., R. N. Hoffman, and J. Ardizzone, A cross-calibrated, multiplatform ocean surface wind velocity product for meteorological and oceanographic applications, Am Meteorol Soc, vol. 92, pp. 157$174,2011$.

[6] Chong wei Zheng and Jing Pan, Assessment of the global ocean wind energy resource, Renewable and Sustainable Energy Reviews, vol. 33, pp. 382-391, 2014. 
[7] Kuang Fangfang, Zhang Youquan, Zhang Junpeng, and Jia Cun. Comparison and evaluation of three sea surface wind products in Taiwan Strait, Haiyang Xuebao, vol. 37, No. 5, pp. 44-53, 2015.

[8] Zheng Chongwei, Sea surface wind field analysis in the China Sea during the last 22 years with CCMP wind field, Meteorology and Disaster Reduction Research, vol. 34, No. 3, pp. 41-46, 2011.

[9] Wang Hui, and Sui Weihui, Seasonal variation analysis of sea surface winds in China Sea areas with CCMP wind field data, Meteorological Science and Technology, vol. 41, No. 4, pp. 720-725,2013.

[10] Katsutoshi Kozai, Teruo Ohsawa, Rinya Takahashi, and Yuko Takeyama, Evaluation method for offshore wind energy resources using scatterometer and Weibull parameters, Journal of Energy and Power Engineering, vol. 6, pp. 1772-1778, 2012.

[11] Tian Pau Chang, Performance comparison of six numerical methods in estimating Weibull parameters for wind energy application, Applied Energy, vol. 88, pp. 272-282, 2011.
[12] Yang Weijun and Wang bin, Fitting to wind velocity of surface layer using two-parameter Weibull distribution function and its application, Quarterly Journal of Applied Meteorology, vol. 10, No. 1, pp. 118122.

[13] Jiang Bo, Zhao Shiming, Ma Zhizhong, Hou Pingping, and Xu Huifen, Temporal-spatial distribution of the wind energy in Liaoning littoral, Marine Sciences, vol. 35, No. 12, pp. 1-8, 2011.

[14] National Development and Reform Commission, China, Technical regulation of wind energy resource assessment, 2004.

[15] Liao Shunbao, Liu Kai, and Li Zehui, Estimation of grid based spatial distribution of wind energy resource in China, Geo-Information Science, vol. 10, No. 5, pp. 551-556, 2008.

[16] Jiang bo, Liu Fuyou, Xu Huifen, Ma Zhizhong, and Zhang Song, Evaluation of the Wind Energy Resources in Zhejiang Coastal Area, Ocean Technology, vol. 31, No. 4, pp. 91-94, 2012. 